\title{
Algo más que piedra y consignas Agitación social vista desde la prensa durante el gobierno de la concentración nacional $(1930-1934)^{*}$
}

\author{
Something else besides stone and slogans:the social \\ agitation seen from the press during the government of the national \\ concentration (1930 - 1934) \\ Recibido: 7 de diciembre de 2008 - Revisado: 12 de febrero de 2009 - Aceptado: 27 de marzo de 2009
}

Rodrigo Hernán Torrejano Vargas*

\section{Resumen}

El artículo es un avance parcial de la investigación acerca de la protesta social en Colombia durante la república liberal (1930 - 1946), en el cual se realiza un examen general de algunos grupos sociales involucrados en las acciones de inconformismo, las modalidades de protesta adoptadas por ellos, sus demandas o exigencias y la localización espacial de los estallidos durante la administración del presidente Enrique Olaya Herrera, basado en información de prensa, para lo cual se hizo un agrupamiento estadístico elemental en tablas y gráficos.

\section{Palabras clave}

Protesta, modalidades de protesta, motivos de protesta, localización de la protesta, grupos inconformes.

\begin{abstract}
This article is a partial advance of the investigation about the social protest in Colombia during the liberal republic (1930 - 1946), in which it is carried out a general and descriptive examination of some social groups involved in the actions of inconformity, the modalities of protest adopted as them, their demands or requirements and the spatial location of the snaps during the administration of the president Enrique Olaya Herrera based on information of press, for which it was statistical elementary grouping in tables and graphs.
\end{abstract}

\section{Key words}

Protests, modalities of protest, motives of protest, location of the protest, nonconformist groups.

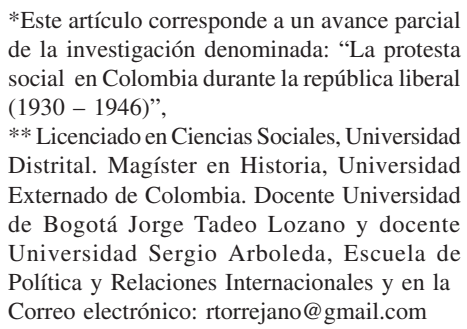

*Este artículo corresponde a un avance parcial de la investigación denominada: "La protesta social en Colombia durante la república liberal (1930 - 1946)",

** Licenciado en Ciencias Sociales, Universidad Distrital. Magíster en Historia, Universidad Externado de Colombia. Docente Universidad de Bogotá Jorge Tadeo Lozano y docente Universidad Sergio Arboleda, Escuela de Política y Relaciones Internacionales y en la Correo electrónico: rtorrejano@gmail.com 


\section{Problema de investigación}

El presente ensayo de historia social colombiana busca responder algunas preguntas acerca de la trayectoria y las visicitudes de la dinámica social experimentada por las diferentes fuerzas vivas de la nación cuando el país venía embarcado en un vertiginoso proceso de modernización capitalista que le estaba cambiando la cara al mundo rural, agrícola y gamonalesco heredado del período decimonónico. Atendiendo con especial cuidado las relaciones que se tejieron entre la modernización económica y el tratamiento que la clase dirigente y empresarial le formularon al "despertar" del inconformismo como mecanismo de inclusión social.

\section{Metodología}

El artículo está en el terreno del colectivismo metodológico, en el que las condiciones materiales son imprescindibles para entender y explicar las relaciones sociales, políticas, jurídicas y culturales, pues estas relaciones no se explican por sí mismas (Fontana, 1982). Enfoque que permite el empleo de conceptos como: lucha de clases, clases sociales, burguesía, clase obrera, etc., y visualizar el funcionamiento social desde la perspectiva de una influencia y condicionamiento general, desplegado sobre todos los hombres por la entidad macro a la cual pertenece, en la que se desenvuelve, sea de manera adaptativa o contestataria y de la cual es producto.

El hombre es fruto de su época y para eso tenemos a nuestra disposición el concepto de modo de producción en el cual discurren las relaciones de clase. Igualmente acoge, por paradójico que pueda parecer, el individualismo metodológico, corriente que toma en cuenta la dimensión individual y racional en la explicación de la conducta de los sujetos y grupos sociales bajo la perspectiva de las teorías de la movilización de recursos y las oportunidades políticas.

\section{Introducción}

Por protesta social se entiende las diversas y disímiles expresiones de descontento, disgusto, inconformismo, enojo, cólera, desazón o pesadumbre, experimentados por diferentes sectores sociales urbanos frente a situaciones estructurales o coyunturales. Entonces, como plantea Mauricio Archila, el tema de la protesta social involucra el estudio de las acciones sociales que "irrumpen en espacios públicos para expresar intencionalmente demandas o presionar soluciones ante distintos niveles del estado o entidades privadas" (Archila, 2005, p 75).

Las protestas sociales son investigadas con el apoyo teórico del colectivismo metodológico porque permite estudiar "un sistema transformable y las condiciones en las cuales se efectúan dichas transformaciones" (Foucault, 2003: 14).

Así mismo, las acciones sociales son escrutadas bajo la lupa del concepto de estructura puesto que delimita, ordena y define sus aspectos internos característicos. Igualmente, este concepto aplica para comprender las relaciones internas que definen la especificidad de la sociedad en la que se inscribe la agitación social (Foucault, 2003: 9 - 10).

Claro está que también se acude al soporte teórico del individualismo metodológico por los lados de la teoría de la movilización de los recursos y la teoría de la estructura de las oportunidades políticas. En la primera de ellas deben recordarse los aportes suscritos por J. McCarthy y M. Zald, quienes subrayan el concepto de maximización de utilidades a la hora de que alguien tome la decisión de involucrarse en cualquier clase de acción social, sondeando el posible provecho que pueda sacar de su participación en un estricto cálculo de costo/beneficio.

Como bien lo expuso la investigadora argentina Marina Farinetti "El camino de la comunidad de intereses a la acción no es espontáneo; requiere de una voluntad empresarial. Digamos que los movimientos sociales se mueven con 
la lógica de una empresa en busca de clientes: procurando la identificación y ofreciendo incentivos" (Farinetti, 2002: 64).

En la segunda corriente se destacan S. Tarrow, Charles Tilly y Doug McAdam, quienes se orientan a comprender, "el motivo por el cual los movimientos no aparecen solo en relación directa con el nivel de quejas de sus seguidores" (Farinetti, 2002: 64), sino con el conjunto de oportunidades de participación social y política ofrecidas por el sistema, es decir, la movilización social está directamente relacionada con la permeabilidad o receptividad del gobierno de turno con el sistema político vigente, sin pretender decir que la inexistencia de ese conjunto de oportunidades políticas elimine o impida la celebración de protestas y movimientos sociales.

Hasta ahora se dispone de una base de datos parcial de las expresiones de inconformismo o malestar social extraída fundamentalmente del periódico EL TIEMPO, el diario de mayor circulación nacional. En el período comprendido entre el 1 de enero de 1930 y el 30 de agosto de 1934 se registraron 137 protestas.

La intensidad de la agitación social varió de un año a otro. Sin embargo, es evidente una tendencia ascendente a medida que el cuatrienio presidencial avanza y más si se compara con el comportamiento de la protesta social a lo largo de los primeros treinta años del siglo en medio de la república conservadora, cuando una base de datos levantada especialmente con información de prensa local arrojó 114 acciones (Torrejano, 2007). El año con mayor número de acciones de inconformismo social fue 1933 con el 33\% de los registros, lo siguió 1934 al alcanzar el 25\%, 1932 ocupó el tercer lugar con el 22.6\%, 1930 ocupó el cuarto puesto con el $16 \%$ y cerró 1931 con un 3.6\% (Véase Tabla No. 1 y Figura 1).

Tabla No. 1. Protestas y agitaciones sociales por año (1930-1934)

\begin{tabular}{|l|l|l|l|l|l|}
\hline & 1930 & 1931 & 1932 & 1933 & 1934 \\
\hline P. social & 22 & 5 & 31 & 45 & 34 \\
\hline
\end{tabular}

Fuente: EL TIEMPO, Bogotá, 1930 a 1934. Archivo General de la Nación, Fondo República, sección $1^{\circ}$ Ministerio de Gobierno.

En promedio, durante cada año de la administración del presidente Olaya Herrera se presentaron 27,4 acciones de protesta social. El promedio mensual de la protesta para cada año del período fue como sigue: 19301,8 acciones; 1931 0,40; 1932 2,6; 1933 3,7 y 1934 2,8 (véase gráfico 1).

Para los años 1930, 1931, 1933 y 1934, el mayor aporte de los actos de inconformismo corrió por cuenta de los trabajadores asalariados de los núcleos urbanos y de los trabajadores cesantes que clamaban por la generación de fuentes de empleo ante los devastadores efectos sociales de la depresión económica.

Para 1932, el panorama de la agitación social es distinto, las manifestaciones y mítines nacionalistas acaecidos a raíz de la ocupación del trapecio amazónico por los peruanos fueron la regla, tanto que 27 de las 31 acciones son de tono nacionalista, es decir, el $87 \%$ (ver tabla 2). Comportamiento que de alguna manera se sostiene el año siguiente, toda vez que 17 de los 45 actos de protesta también corresponden al mismo motivo (38\%).

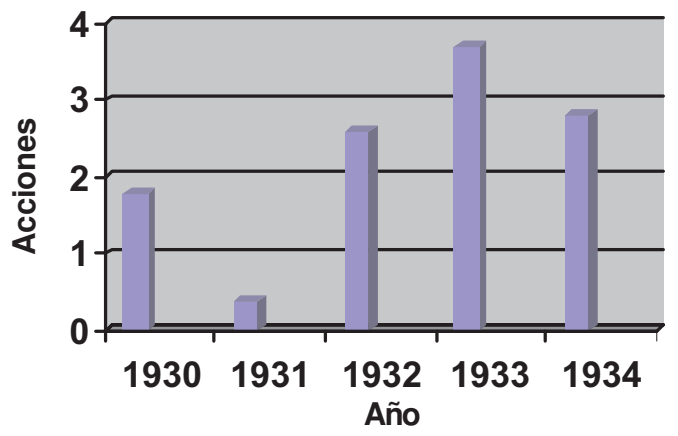

Figura 1. Protesta y agitaciones por año

Fuente: EL TIEMPO, Bogotá, 1930 a 1934. Archivo General de la Nación, Fondo República, sección $1^{\circ}$ Ministerio de Gobierno. 
Al lado de las expresiones sociales de corte laboral y nacionalista o junto con los inquietos y diligentes núcleos de trabajadores asalariados activos y cesantes, como de gente proveniente de todas las clases y sectores sociales, confundidos bajo la misma bandera de defensa de la soberanía nacional, los estudiantes de secundaria y de las universidades vienen ganando un espacio propio en la agenda social en búsqueda de la autonomía universitaria, la calidad de la educación y el acceso a la educación superior. Son frecuentes las huelgas estudiantiles que paralizan por varios días la vida académica y dinamizan tanto el ambiente social y político de la región como del país.
El año más agitado en esta materia fue 1934 con 9 de 33, el 27,27 (véase Tabla 2), siendo la razón el enojo de los jóvenes, el Decreto 1074 de mayo 23 de 1934 que consagraba como requisito indispensable para ingresar a la universidad, oficial y privada, la rendición previa de un examen de cultura general que versará sobre las siguientes materias: aritmética, álgebra, geometría, ciencias naturales, física, química, historia patria, geografía, filosofía, francés, inglés y latín, con la salvedad siguiente, los aspirantes a seguir estudios de derecho presentarán examen en latín y en francés o inglés, a la suerte, los demás no están obligados a la presentación de la prueba de latín, siempre y cuando comprueben que se ha aprobado dicha asignatura.

Tabla No. 2. Composición de la protesta y agitación

\begin{tabular}{|l|l|l|l|l|l|}
\hline MOTIVO & $\mathbf{1 9 3 0}$ & $\mathbf{1 9 3 1}$ & $\mathbf{1 9 3 2}$ & $\mathbf{1 9 3 3}$ & $\mathbf{1 9 3 4}$ \\
\hline Demandas laborales & 17 & 2 & 3 & 17 & 18 \\
\hline Demandas nacionalistas & 0 & 1 & 27 & 17 & 0 \\
\hline Demandas educativas & 5 & 2 & 1 & 1 & 9 \\
\hline Otras & 0 & 0 & 0 & 10 & 6 \\
\hline Total & 22 & 5 & 31 & 45 & 33 \\
\hline
\end{tabular}

Fuente: EL TIEMPO Bogotá, 1930 a 1934. . Archivo General de la Nación, Fondo República, sección $1^{\circ}$ Ministerio de Gobierno.

El segundo año de gran agitación estudiantil se desencadenó en 1930 con 5 de 22 , el $22,7 \%$ (Ver tabla 2), en el que estudiantes y algún sector de los profesores conforman una alianza política para exigir varios cambios administrativos que conduzcan al mejoramiento de la calidad de la educación y a la participación democrática de los jóvenes en los consejos directivos de las facultades.

De menor importancia cuantitativa fueron las protestas de los conductores de servicio público alarmados por el impagable monto de la multas de tránsito que cargan a cuestas por la constante trasgresión de las normas vigentes de circulación y, en ocasiones, la agitación y contrariedad sufrida por los empresarios del transporte público de carga ante la negligencia de las autoridades civiles para conservar en buen estado las vías departamentales, así como las manifestaciones de algunos grupos ante el aumento de los cánones de arrendamiento, sin que nunca sus acciones pudieran compararse con las que emprendieron las ligas de inquilinos durante la década del veinte.

\section{Distribución espacial de la protesta social}

De acuerdo con nuestra base de datos una región muy conflictiva del país es la zona Andina alcanzó el $66 \%$ de los estallidos de irritación social, el segundo lugar es para Caribe con el $22 \%$ y el tercer puesto lo ocupa la región pacífica al revelar el 9,2\%, el resto corresponde al actual departamento de Amazonas.

Esta distribución espacial no es nada sorprendente si consideramos que en las dos primeras 
regiones está concentrada la actividad económica y los núcleos urbanos.

Una mirada un poco más detallada del origen geográfico de la protesta en el interior de cada región natural, permite establecer que en la zona andina los departamentos de Cundinamarca, Antioquia y Caldas se llevaron los tres primeros lugares al representar el $34,11 \%, 16,5 \%$ y $14,11 \%$ respectivamente, de un total de 85 acciones de inconformismo.

En la región Caribe, los departamentos más conflictivos fueron en orden descendente: Atlántico, 57\%; Bolívar, $32 \%$ y Magdalena $11 \%$. En la pacífica, la cuestión de la escala departamental de la conflictividad fue así: Valle, 83,3\%; Cauca, 8,33 y Nariño 8,33\% (véase Tabla 3).

Tabla No. 3. Distribución regional y departamental de la protesta y la agitación social (1930 - 1934)

\begin{tabular}{|l|l|c|}
\hline REGIÓN & DEPARTAMENTO & No. DE PROTESTAS \\
\hline Andina & 1. Cundinamarca & 29 \\
\hline & 2. Antioquia & 14 \\
\hline & 3. Caldas & 12 \\
\hline & 4. Norte Santander & 8 \\
\hline & 5. Santander & 8 \\
\hline & 6. Boyacá & 5 \\
\hline & 7. Tolima & 5 \\
\hline Caribe & 8. Quindío & 3 \\
\hline & 9. Huila & 1 \\
\hline & 1. Atlántico & 16 \\
\hline Pacífica & 2. Bolívar & 9 \\
\hline & 1. Valle & 3 \\
\hline & 2. Cauca & 10 \\
\hline
\end{tabular}

Fuente: EL TIEMPO, Bogotá, 1930 a 1934. Archivo General de la Nación, Fondo República, sección $1^{\circ}$ Ministerio de Gobierno.

De Igual manera, los departamentos que encabezan la lista de conflictividad social en cada una de las tres regiones naturales mencionadas, junto con Antioquia, son los polos de desarrollo capitalista que expresan un cambio estructural trascendental en lo concerniente a la composición de la actividad económica cuando empieza a notarse la ampliación de la participación de los sectores secundario y terciario frente al agropecuario, que entre otros efectos sociales desencadena una transformación de la estructura ocupacional o del empleo por cuanto la población empleada en la industria, el comercio, el transporte, los servicios, las comunicaciones y las finanzas aumenta, en tanto 
la población contratada en actividades primarias se retrae (Ocampo, 1991), generando una movilización demográfica hacia las urbes y la proliferación de formas de trabajo asalariado que será, como se observa en la Tabla 2, uno de los móviles disparadores del desgano y la furia social popular a lo largo del período político de la concentración nacional.

De esta manera, es sensato afirmar que la protesta social se mueve de la mano con la modernización capitalista. En otras palabras, existe una relación directa entre los avances del capital, el cambio de la estructura ocupacional, la migración del campo hacia la ciudad y el despliegue del inconformismo social hacia las grandes y pequeñas urbes, siendo las primeras: Bogotá, Medellín, Barranquilla y Cali, entre las segundas, las demás capitales de departamento, sin decir por ello que el campo haya dejado de ser un espacio político en el que la protesta social alrededor de la propiedad de la tierra y la demanda de una transformación de las relaciones de trabajo no asalariado en las haciendas se hubieran esfumado o que para la década del treinta Colombia hubiera abandonado su perfil agrario y rural, pues es a partir de la década del sesenta que la población urbana supera a los núcleos demográficos campesinos (ver tabla 4).

Tabla No. 4. Población total y concentración urbana

\begin{tabular}{|c|c|c|c|}
\hline A ÑNO & TOTAL & URBANA 1 & RURAL \\
\hline 1912 & 5.073 .000 & n. d. & n. d. \\
\hline 1918 & 5.855 .000 & n. d. & n. d. \\
\hline 1938 & 8.702 .000 & 2.692 .000 & 6.010 .000 \\
\hline 1951 & 11.548 .000 & 4.468 .000 & 7.080 .000 \\
\hline 1964 & 17.485 .000 & 9.093 .000 & 8.391 .000 \\
\hline 1973 & 22.915 .000 & 13.580 .000 & 9.335 .000 \\
\hline 1985 & 27.867 .000 & 18.735 .000 & 9.132 .000 \\
\hline
\end{tabular}

\section{Composición social de la protesta}

El examen de las diferentes acciones de inconformismo social pone en evidencia que los trabajadores asalariados, los estudiantes y los profesores son los grupos sociales más dinámicos de la protesta urbana; son los que mayor actividad contestataria desplegaron, no solamente a lo largo del período presidencial de Enrique Olaya Herrera, sino durante todos los años del naciente siglo XX.

Sin ninguna duda, los trabajadores asalariados ocuparon el primer lugar desde el principio, particularmente desde la segunda década del siglo, mediante la modalidad de la huelga como instrumento de movilidad, agitación y presión social, modalidad que adoptaran los estudiantes en la búsqueda de sus objetivos grupales específicos.

De las 136 acciones integrantes del espectro de agitación social del período, 48 de ellas, el $35,30 \%$, son de índole estrictamente laboral, mientras las expresiones de descontento estudiantil fueron 18 , lo cual corresponde al $13,23 \%$. A continuación estuvieron los conductores de servicio público de pasajeros con 8 expresiones, el $5,9 \%$ y en el cuarto puesto los presos, el 3,7\% al emprender 5 huelgas (ver tabla 5). 
Tabla No. 5. Grupos sociales involucrados en la protesta

\begin{tabular}{|l|c|c|c|c|}
\hline AÑO & $\begin{array}{c}\text { Trabajadores } \\
\text { asalariados }\end{array}$ & Estudiantes & Conductores & Presos \\
\hline $\mathbf{1 9 3 0}$ & 11 & 5 & 0 & 0 \\
\hline $\mathbf{1 9 3 1}$ & 1 & 2 & 1 & 0 \\
\hline $\mathbf{1 9 3 2}$ & 2 & 1 & 0 & 0 \\
\hline $\mathbf{1 9 3 3}$ & 16 & 1 & 4 & 3 \\
\hline $\mathbf{1 9 3 4}$ & 18 & 9 & 3 & 2 \\
\hline
\end{tabular}

Fuente: EL TIEMPO, Bogotá, 1930 a 1934. Archivo General de la Nación, Fondo República, sección $1^{\circ}$ Ministerio de Gobierno.

De manera paralela, a las expresiones particulares de disgusto realizadas por los diversos grupos sociales, hubo un significativo grupo de acciones en la cual las fronteras socioeconómicas y políticas se diluyeron por períodos brevísimos, gente procedente de todos los sectores sociales fueron convocadas y reunidas alrededor de la fuerza aglutinante, adhesiva y cohesiva de la nación.

Decenas de acciones multitudinarias y pluriclaisistas subordinaron los intereses de clase o de grupo frente a la defensa de la soberanía territorial. Entre 1932 y 1933 sucedieron 45 manifestaciones nacionalistas pacíficas en varias ciudades del país, el 33\% del total de acciones, exteriorizando su incondicional respaldo al gobierno del Presidente Olaya Herrera y los derechos de propiedad del Estado Nación sobre el trapecio amazónico de acuerdo con las cláusulas del tratado público Salomón - Lozano firmado en Lima el 24 de febrero de 1928 entre el Plenipotenciario peruano Alberto Salomón, Ministro de Relaciones Exteriores y el Plenipotenciario de Colombia Fabio Lozano, registrado en la novel organización multilateral de la Sociedad de las Naciones el 29 de mayo de 1928 , lo que deja a las protestas nacionalistas en el segundo renglón después de los gestos de disgusto de los trabajadores asalariados.

\section{Objetivos de la protesta social}

Si tomamos de referencia los sectores sociales más dinámicos, expresivos y explosivos del período: trabajadores asalariados, estudiantes, conductores y presos, resulta clave inspeccionar las razones inherentes a su molestia.

En cuanto a los asalariados, estuvieron agolpados alrededor de varias fuentes de perturbación social, a saber: el desempleo, la disminución del salario, la exigencia de un mejor pago y la innovación tecnológica. El primer móvil fue un factor fuerte y dramático durante 1930, siete de las once protestas registradas tuvieron relación directa con la contracción del empleo efecto de los síntomas de la depresión del 29, para caer estrepitosamente los siguientes cuatro años del período, pues entre 1931 y 1934 sólo estallaron dos protestas más por esta circunstancia.

El segundo móvil es otro de los efectos sociales que trajo consigo la depresión económica del 29, porque algunos trabajadores que pudieron conservar sus puestos de trabajo se vieron sometidos a la política de reducción de costos adelantada por los empresarios para enfrentar el colapso del mercado, teniendo también lugar en 1930 y desapareciendo en el resto del período. 
El tercer móvil es el más común y recurrente, no obstante, tuvo la singularidad de comportarse de manera inversa a los dos móviles anteriores, al permanecer en un estado social de hibernación los tres primeros años del gobierno de Olaya Herrera y despuntar con brío a partir de 1933, situación que logra entenderse a la luz de la llegada de los primeros síntomas de recuperación de la economía nacional.

El cuarto móvil es una curiosidad social en nuestro medio, se trató de la campaña de oposición de los trabajadores de la empresa de Tejidos Obregón, pionera de la industria textil, contra la instalación de ocho telares nuevos porque la disposición dejaría sin trabajo a muchos compañeros

Los estudiantes, de manera especial los jóvenes universitarios de provincia, protagonizarían manifestaciones de absoluto carácter pacífico y negociador tras la consecución de varias metas gremiales, Una de las metas más visibles fue la cruzada a nivel institucional por la defensa de la calidad de la educación superior. Otra meta, igualmente perceptible, apuntó hacia la introducción de una reforma administrativa en la educación superior que les permitiera tener representación en el Consejo Directivo, para cerrar con las denuncias de las arbitrariedades administrativas cometidas por las autoridades escolares.

Los conductores, por su parte, actuaron al amparo de dos grandes preocupaciones, una de grafía bien específica y otra de interés más general. En lo primero matriculamos los paros dirigidos a denunciar los presuntos abusos de las autoridades de transporte y el excesivo celo punitivo de sus funcionarios que los tenían lidiando con la pesada carga de las multas de tránsito. En lo segundo están las movilizaciones en procura de inversión estatal en infraestructura vial. Por último, los presos piden la palabra y denuncian la ausencia del debido proceso en sus casos.

\section{Formas de la protesta social}

Aquí entra la manera, el modo, el estilo, el talante o el procedimiento dispuesto por los diversos sectores sociales para afrontar los problemas y retos que los afectan. Para Mauricio Archila Neira las formas de protesta son las mismas modalidades de lucha que adopta la acción social en búsqueda de la modificación de la conducta de otros y que para el período por él analizado en libro Idas y Venidas, Vueltas y Revueltas de las protestas sociales en Colombia (1958 - 1990) adquieren diez formas: huelgas, movilizaciones, invasiones de predios, bloqueos, disturbios, ocupación de fábricas, cabildo abierto, operación vela, huelga de silencio y disturbios, entre los que clasifica el motín, la asonada y la pedrea (Archila, 2005).

Para el historiador social francés George Rudé el tema de las formas de protesta pasa por el cedazo metodológico del papel y el lugar que debe jugar en la historiografía mundial la multitud o la muchedumbre, así como el interés por encontrar las maneras típicas de protesta del pasado para períodos específicos de la historia, por lo que llega a establecer que en Europa occidental, particularmente en Inglaterra y Francia, durante la época de transición al capitalismo en los siglos XVII y XVIII, la revuelta del hambre fue la forma típica de ese mundo rural y feudal en decadencia, y la huelga lo sería del capitalismo industrial que estaba gestándose (Rudé, 1979).

Para estos primeros años de la década del treinta, tenemos un conjunto de formas de protesta compuesto por: huelgas, movilizaciones, huelgas de hambre, asonadas y mítines, la mitad de las formas que registra Archila para después de la Segunda Guerra Mundial. La huelga y la movilización fueron los instrumentos de presión social más implementados por todos los sectores sociales. La huelga distó de ser un mecanismo de lucha social exclusivo de los trabajadores asalariados, los estudiantes recurrieron a ella en innumerables oportunidades para expresar su inconformismo gremial, tal vez porque consideraban que era un mecanismo expedito de lucha social que había ofrecido una balance positivo para la clase trabajadora que podía beneficiarlos a ellos de la misma manera. 
La huelga de hambre, la asonada y el mitin constituyeron mecanismos subalternos de agitación, convocatoria y presión. La información de prensa apenas identifica cinco huelgas de hambre en el país, todas ellas realizadas por presos que claman por la aplicación del debido proceso judicial, junto con dos tremendas asonadas, una en 1930 y otra en 1934.

\section{Dinámica de la protesta social}

A continuación, se hará una descripción pormenorizada de los acontecimientos propios de las diferentes acciones de inconformismo social para revelar detalles de las ambiciones latentes y los mecanismos de agitación utilizados por los actores involucrados.

\section{Protesta educativa}

Sin ninguna duda, los estudiantes, especialmente universitarios, jugaron un destacado papel en el escenario social (véase Tabla 2). La huella que marca el inicio de su protagonismo en el período analizado fue la operación conjunta con los profesores de la Facultad de Medicina de la Universidad de Cartagena a principios de abril de 1930 con el ánimo de emprender una cruzada institucional por la calidad de la educación y la participación democrática de los estudiantes en el Consejo Directivo de la Facultad.

En cuanto a la calidad de la educación, los estudiantes y un sector de los profesores, aúnan esfuerzos para presentar un proyecto común de reforma administrativa a las directivas de la universidad y los diputados de la Asamblea Departamental con miras a la supresión de procedimientos oscuros anclados en el nepotismo y el clientelismo a la hora de seleccionar la planta de profesores, disponiendo de mecanismos democráticos, claros y transparentes de contratación laboral atados al mérito y la experiencia profesional, ya que la transformación de la política de contratación podría garantizarles una educación de más y mejor calidad. Eso explica que en el memorial de agravios que pasaron los organizadores a las directivas y diputados pidieran: "retiro de profesores inaptos", "defensa de profesores idóneos", "concurso para internados cada seis meses" y "jefes de clínica por concurso" (EL TIEMPO, № 6652, 1930, 7 de abril).

Por otra parte, en el memorial sobresale una petición de exclusivo acento estudiantil, cual fue el énfasis que se le imprimiría a la urgente necesidad de concedérseles participación en el Consejo Directivo de la Facultad, sin que en el futuro dicha institución pueda sesionar sin la presencia del representante de los estudiantes (EL TIEMPO №6651, 1930, 6 de abril).

El proyecto de reforma administrativa siguió su curso en la Asamblea Departamental sin que el nivel de tensión y ansiedad decayera entre la comunidad educativa de la facultad de medicina. Por el contrario, la zozobra se apoderó de ellos que convocaron una primera movilización que se celebraría el 27 de abril ante la Asamblea y otra dos días después por la principales calles de la ciudad, en razón a que el Secretario de Educación del departamento, un señor de apellido Botett, expresó públicamente su disentimiento frente al proyecto de reforma presentado a la Asamblea, por lo que ahora también exigirán la renuncia del funcionario público o de lo contario convocarían a un paro estudiantil indefinido, que de hecho entró en vigor los primeros días del mes de mayo (El Tiempo, №6670/72, 1930,28/30 de abril).

La presión estudiantil va en imparable ascenso toda vez que las demandas crecen cuando solicitan no sólo la renuncia del Secretario de Educación, sino del Consejo Directivo de la Universidad, integrado por Fidel Pérez, Luís Carlos Medina y Antonio Díaz Granados, por ser partícipes de la oposición al proyecto de reforma, por lo que fue nombrada una "junta de notables" con el propósito de mediar en el conflicto, siendo sus miembros: Simón Bossa, Antonio José de Irisarri, Gómez Fernández, Obregón, Lozano y Leyva (EL TIEMPO, №6673, 1930. 1 de mayo). Los datos publicados unos pocos días después 
advierten que la presión ejercida para precipitar la renuncia del Secretario de Educación surtió efecto. El Gobernador del Departamento envió al Ministro de Educación una terna para escoger el reemplazo entre estos candidatos: José de Irisarri, Napoleón Franco y José María Lozano, quien a la postre resultó nombrado, e igualmente sobrevino la caída del Rector de la Facultad, para lo cual fue nombrado Carlos Esguerra, procediendo a la organización de un nuevo Consejo Directivo comprometido con el proyecto de reforma en curso, siendo sus miembros: Miguel Jiménez López, Jorge Bejarano, Jorge Cavelier y Julio Aparicio (EL Tiempo, N-6678.1930, 7 de mayo).

Tal vez el efecto inmediato más trascendental de las movilizaciones y el paro de los estudiantes de medicina de Cartagena consistió en que se constituyeron en una especie de paradigma. Los ecos del paro no tardaron en sentirse en la vecina ciudad de Barranquilla, donde los estudiantes del colegio del mismo nombre se declararon en paro el 30 de abril para pedir el cambio de rector por considerarlo incompetente y cambio de profesores, quejándose de su falta de puntualidad a la hora de dictar las clases. La respuesta por parte del gobernador es oportuna al expedir el 3 de mayo una norma mediante la cual nombró siete profesores nuevos (El Tiempo, № 6675, 1930, 4 de mayo).

En la misma ciudad de Cartagena el inconformismo universitario levanta la solidaridad de las alumnas del Colegio del Carmen, quienes además presentaron un memorial a las directivas del claustro en el que lanzan un ultimátum: cambian varios docentes que no satisfacen sus expectativas de calidad o se declaran en huelga. Esto sin poder pasar por alto la adhesión de los estudiantes de la Escuela Nacional de Veterinaria al proyecto de reforma universitaria (El Tiempo, №6691, 1930, 20 de mayo).

Otro eco ocurre unos pocos meses después, a principios de julio, entre los estudiantes del colegio San Luis Gonzaga en el municipio cundinamarqués de Zipaquirá, regentado por los padres del Corazón de María, motivado, a simple vista, por la expulsión de un grupo de alumnos decretada por el rector Pedro Atucha. Situación que no fue mas que el caballo de Troya usado por los estudiantes para promover la presentación de un pliego de peticiones ante el Ministro de Educación, que tenía como objetivo central la implementación de un proyecto de reforma administrativa del mismo talante de la que había orientado las acciones de los estudiantes universitarios y de secundaria en Cartagena y Barranquilla. Las peticiones concretas fueron: cambio del rector, mejoramiento y aumento del profesorado, creación del Consejo Directivo y elaboración de un reglamento de admisión (EL Tiempo, $\mathrm{N}^{\circ}-6736,1930,4$ de julio).

Pero los efectos no se detuvieron aquí. En abril de 1931 los estudiantes de secundaria del Liceo Celedón de Santa Marta declararon la huelga en procura de una serie de objetivos: primero, la destitución del rector Teodosio Goenaga por "incompetente"; segundo, conquistar la participación de los estudiantes en el Consejo Directivo; tercero, lograr la destitución inmediata de varios docentes y, cuarto, adquirir material de física y química (El Tiempo, №7028, 1931, 27 de abril). Evento que cerró la etapa de las protestas desencadenadas por el deseo de participación democrática y la búsqueda de calidad docente en algunos programas profesionales y colegios.

Otro espectro del malestar estudiantil tiene relación directa con las presuntas arbitrariedades cometidas por algún directivo docente. Eso es lo que deja entrever la manifestación pacífica de estudiantes internos del colegio San Simón de Ibagué el 27 de septiembre de 1931, cansados de los ultrajes que les hacia el Vicerrector Anzola Gómez. La manifestación tomó rumbo hacia la casa del Director de Educación del departamento en demanda de la inmediata destitución del funcionario, quien les notificó que regresaran al colegio en el término de diez minutos so pena de quedar expulsados de él, amenaza que lejos de 
menguar o aniquilar la fuerza de la protesta la acentuó encaminándola hacia la casa del gobernador donde se diluyó ante la promesa de una pronta indagación de los sucesos. Al día siguiente la esperanza puesta en la gestión diligente del gobernador se vino al piso al conocerse que se les había impuesto el castigo de recibir la más baja nota de calificación de conducta durante el resto del año y privándolos de salida (El Tiempo, № 7181, 1931, 28 de septiembre). Por el mismo lado camina la manifestación cumplida el 23 de abril de 1932 en Manizales ante la gobernación rechazando la determinación del Consejo Directivo del Instituto Universitario de expulsar a varios alumnos por haber mostrado en la Asamblea Departamental un memorial reclamando la reforma de dicho ente (EL TIEMPO, №-7386,1932, 24 de abril 24).

Tal parece que el agitado ambiente reinante en varias instituciones educativas del país, sobre manera lo relacionado con la exigencia de calidad académica por cuenta de los docentes, puso en estado de alerta permanente a algunos, eso es por lo menos lo que se colige de la acalorada polémica terciada en el seno de la Escuela de Medicina de la Universidad de Antioquia a principio de mayo de 1932, cuando un grupo de profesores dirigió una nota al Consejo solicitando se cancelara la matrícula de los quince estudiantes que en días pasados se habían atrevido a reclamar la renuncia del doctor Alfonso Castro de la cátedra de patología, por considerarlo un auténtico ultraje, de lo contrario ellos presentarían renuncia irrevocable, lo cual condujo a la celebración de una movilización de quinientos estudiantes que se encaminaron al palacio de la gobernación gritando no sólo vivas a la universidad, sino objetando la posición de sus profesores (El Tiempo, №-7394, 1932, 3 de mayo 3).

La calma en los claustros reinó alrededor de un año. A finales de abril de 1933 el malestar vuelve a sentirse, en esta ocasión el sismo se siente en la facultad de derecho de la Universidad Nacional de Bogotá. A diferencia de las acciones de los años anteriores la forma de protesta esgrimida no fue ni la movilización ni el paro, ahora acudieron al memorial. Instrumento bastante inusual que desplegaron los representantes de los estudiantes de la facultad para dirigirse al rector y a los miembros del Consejo Directivo requiriendo la renuncia colectiva del profesorado, la reforma del reglamento estudiantil y doble representación de los alumnos en el Consejo Directivo. Al cabo de lo cual lanzaron el ultimátum de que si sus ambiciones eran insatisfechas se declararían en huelga permanente (EL TIEMPO, №-7748, 1933, 27 de abril).

Al pliego se adhirieron estudiantes de las Universidades Libre y Externado. Una vista detallada del pliego estudiantil permite capturar estas peticiones: ningún profesor puede servir más de una cátedra, nombramiento de profesores agregados, modernización y ampliación de la biblioteca, adquisición de una imprenta o en su defecto destinar una partida con el objeto de fundar una revista (El Tiempo. № -7758, 1933, 7 de mayo). La respuesta adoptada por los miembros del Consejo Directivo consistió en el cierre de la facultad mientras se llegaba a un acuerdo, el cual nunca llegó.

Tras otro período de receso la agitación retorna a la escena social en el departamento de Caldas. A principios de abril de 1934 un sector de los estudiantes del Instituto Universitario de Manizales, los externos, dirigió un memorial a la Asamblea Departamental exigiendo el cambio del Rector Julio Ángel, por considerarlo incompetente al ser ignorante en tópicos de pedagogía e incapaz de imponer la disciplina en el plantel. El memorial se vio acompañado de un mitin en el recinto de la Asamblea Departamental donde expresaban su gratitud a los diputados que amparaban su causa, en particular a Jorge Luís Vargas, quien propuso fijar la elección del rector. Entre tanto, el sector estudiantil de los internos o becarios siempre estuvo de parte del directivo, al igual que el gobernador y la mayoría de diputados (El Tiempo, № 8093 y 8094, 1934, 12/13 de abril).

Casi quince días después la desazón entra por la puerta grande de la Facultad de Pedagogía en 
Tunja. El incidente que precipitaría la animadversión de estudiantes y profesores corrió por cuenta de la fulminante destitución de Vicente Castellanos de la Vicerrectoría, tomada por la Junta Asesora de la Secretaría de Instrucción Pública y el Secretario de Instrucción Pública, Antonio José Sánchez, aunque el fondo del asunto, en opinión de él, tenía directa relación con la mala prensa que recibió por cuenta de un sector de profesores que le habían hecho creer a la comunidad estudiantil que iba a suprimir las becas de que disfrutan, propalando, así mismo, el rumor de que varios profesores serían retirados sin justa causa (EL TIEMPO, № 8119 , mayo 9 de 1934).

La oposición al Secretario de Educación vino a concretarse con una movilización ocurrida el 29 de abril en la que sus participantes demandaron la destitución inmediata del funcionario público, declarándose en huelga hasta que se cumpliera el objetivo trazado, que por cierto se torna real cuando él presenta renuncia irrevocable a su cargo el 8 de mayo y se encarga de la secretaría Hernán Salamanca (El TIEMPO № 8120 , 1934, 10 de mayo).

Pero sin ninguna duda, el acontecimiento que precipitaría el disgusto generalizado del estamento estudiantil a nivel nacional fue la expedición del Decreto 1074 de 1934 de conformidad con lo dispuesto en los Artículos 9, 10,11 y 12 de la Ley 56 de 1927, que consagraba como requisito indispensable para ingresar a la universidad, oficial y privada, la rendición previa de un examen de cultura general. Examen que versaría sobre las siguientes materias: aritmética, álgebra, geometría, ciencias naturales, física, química, historia patria, geografía patria, filosofía, francés, inglés y latín, siendo este último únicamente obligatorio para los aspirantes a seguir estudios de derecho, siempre y cuando se comprobara que se hubiera aprobado la asignatura. El examen de cultura general se consideraba aprobado al obtener una nota igual o superior a 3.0 en cada una de las materias, la perdida de solo una de estas áreas daba para que fuese reprobado.
Hacia los primeros días de junio se siente, en Bogotá, la presencia del Comité General de Organización Estudiantil, encargado de generar un estado de alarma extendido que pudiera convertirse en un movimiento social encaminado a buscar la derogatoria de la norma dado que la consideraban lesiva para las aspiraciones personales y familiares de los bachilleres del país pues se trata de un filtro o proceso darwinista de decantación de acceso a la educación superior, porque adiciona unas materias que no venían siendo evaluadas, cuando la esencia de las pruebas anteriores al nuevo decreto era que el examen versaba sobre las materias necesarias para adelantar estudios profesionales en determinada facultad. A lo que debe añadirse la incomodidad experimentada por los estudiantes bachilleres de provincia por la presunta decisión de centralizar la presentación de las pruebas nacionales en la capital del país para ingresar a cualquiera de las facultades de la patria, decisión, que por cierto, no viene contemplada en dicho decreto.

En Bogotá, por lo menos, el Comité General integrado por Pedro Gutiérrez, Gómez Trujillo y Lozano Medina se dieron a la tarea de visitar el mayor número de colegios posibles advirtiendo del carácter nocivo de la medida y el 5 de junio pasaron por los colegios: Ramírez, Santander y Escuelas Unidas. Entre tanto, el clima también estaba agitado en provincia, manifestaciones estuvieron a la orden del día en Popayán, Manizales, Medellín, Cartagena y Santa Marta, ciudad en la que la tensión creció cuando los estudiantes del conocido Liceo Celedón proclamaron la huelga en señal de desaprobación de la medida oficial (EL TIEMPO, №-8149, 1934, 8 de junio).

En todo caso la agitación provocó inquietud en el gobierno central, el ministro de educación de aquellos años, Jaime Jaramillo Arango, salió con prontitud y celeridad a anunciar que se estaba repasando el decreto que le daba vida a los nuevos exámenes de "revisión y cultura general", por ello venía preparándose uno nuevo. 
Lo cierto es que el sentido de ser del nuevo examen fue defendido no solamente desde las toldas del gobierno, sino desde el sector privado por parte de algunos analistas. Ese fue el caso del reconocido escritor y educador Tomás Rueda Vargas, Director de la Biblioteca Nacional y Rector del Colegio Nacional, quien defendió la norma argumentado que cualquier profesional debe llevar consigo los principios de la cultura universal. Así lo escribió en una columna del periódico EL TIEMPO: "El ingeniero, el médico, el abogado van a ser miembros de las clases dirigentes, y si no llevan del colegio los principios generales de cultura universal, harán un pobre papel...." (EL TIEMPO, $\mathrm{N}^{\mathrm{o}} 8162,1934,21$ de junio 21).

Y remata de la siguiente forma:

Hagan los estudiantes en buena hora huelgas y aún revoluciones, siempre que tropiecen con un mal profesor, con un rector negligente, con un gobierno injusto; pero no gasten sus jóvenes energía en defender los fueros de la ignorancia integral, contra quienes trabajan desde arriba por seleccionar el personal universitario. (El Tiempo, $N^{\circ}$ 8162, 1934, 21 de junio).
Comentario anclado, muy seguramente, en los pobres resultados de las pruebas académicas presentadas por los bachilleres del país, de ahí que se hubieran divulgado algunas respuestas ofrecidas por los estudiantes de segunda enseñanza en la prueba. A manera de ejemplo: "el barómetro sirve para medir la temperatura de un lugar" (EL TIEMPO, $\mathrm{N}^{\circ}, 8150,1934,9$ de junio).

\section{Protesta asalariada}

De acuerdo con nuestra base de datos, los grupos más beligerantes de la clase social obrera colombiana estuvieron representados por los trabajadores de los sectores del transporte y la industria de bienes de consumo.

En el primer caso efectuaron 15 actos de protesta, exactamente el $33 \%$; en el segundo 14 jornadas, que corresponden al $30 \%$ (véase Tabla 6 ). Vale la pena destacar que entre los trabajadores del transporte los más dinámicos fueron los braceros del ferrocarril y los puertos, tanto fluviales como marítimos, llamaron a la agitación en 11 de las 15 oportunidades, es decir, el $73 \%$ de las veces, el resto correspondió a otra clase de desempeño laboral dentro del ferrocarril.

Tabla No. 6. Actividad económica en la cual se desarrolla la protesta 1930 -1934

\begin{tabular}{|l|c|c|c|c|c|}
\hline Actividad & $\mathbf{1 9 3 0}$ & $\mathbf{1 9 3 1}$ & $\mathbf{1 9 3 2}$ & $\mathbf{1 9 3 3}$ & $\mathbf{1 9 3 4}$ \\
\hline Transporte:braceros ferrocarril y puertos & 2 & & & 7 & 2 \\
\hline Transporte: trabajadores del ferrocarril & & & & 2 & 2 \\
\hline Industria del calzado & & & & 4 & 3 \\
\hline Industria de alimentos: panadería & 1 & & & & \\
\hline Industria de alimentos: trilladoras & & & & & 2 \\
\hline Industria de bebidas: cervecerías & & & & 2 & \\
\hline Industria textil & & & & & 2 \\
\hline Obras públicas: carreteras & 2 & & & & \\
\hline Industria editorial: tipógrafos & & & & & 1 \\
\hline Industria de vidrio & & & & 1 & \\
\hline Albañiles & & & & & 1 \\
\hline Paileros & & & & 1 & \\
\hline Desempleados & 7 & & 1 & & 1 \\
\hline Combinada & & & & & 2 \\
\hline
\end{tabular}

Fuente: EL TIEMPO, Bogotá, 1930 a 1934. Archivo General de la Nación, Fondo República, sección 1 Ministerio de Gobierno. 
En lo que concierne a los trabajadores de la industria de bienes de consumo se destaca el papel ejercido por los obreros de la industria de calzado, pues en 7 de las 14 ocasiones de descontento pusieron la cara, o sea, el 50\%. Enseguida vinieron los asalariados de las cervecerías y las textileras, al igual que las escogedoras de las trilladoras, cada grupo con dos acciones respectivamente, cada uno el $14 \%$, para un total de $42 \%$.

Algo que no puede pasar desapercibido, es el peso considerable de las expresiones de malestar de los desempleados, fueron 9 de 46 acciones, el $19,5 \%$, el tercer lugar en orden descendente, sobre todo al comienzo del período en 1930. Por otra parte, algo particular es que el descontento de los trabajadores asumió un comportamiento ascendente por cuanto en 1930 se escenificaron 12 expresiones, en 1933, 17 y en 1934, 16, con dos años de calma, 1931 y 1932 (véase gráfico 2). Panorama que da a entender que la agitación laboral se incrementa a medida que la economía mundial y nacional va recuperándose progresivamente.

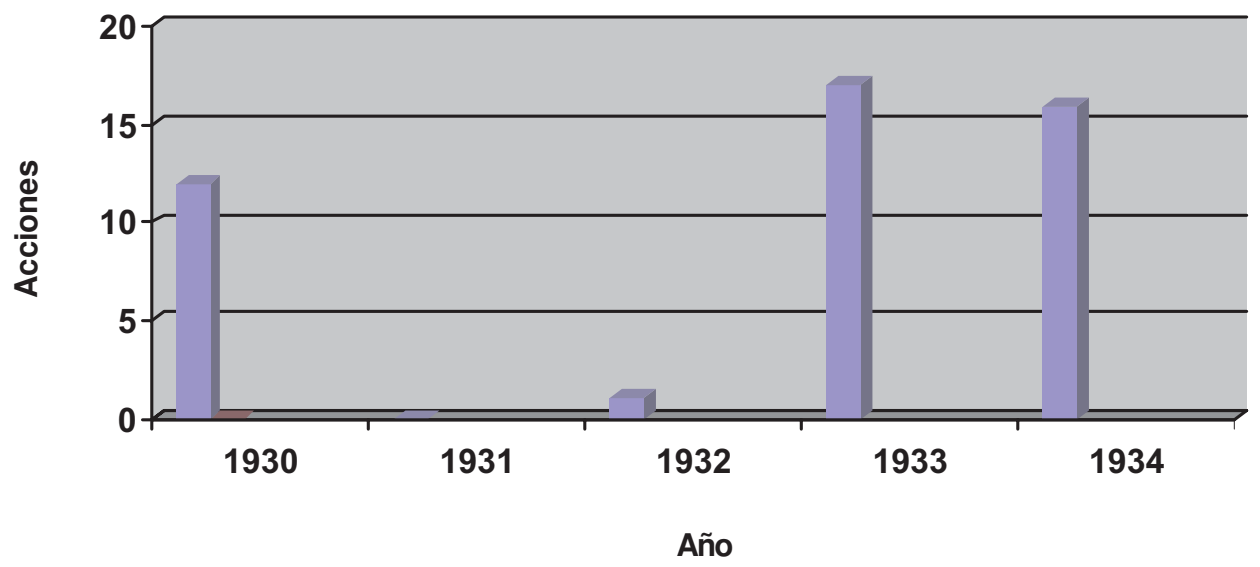

Figura 2. No. Acciones realizadas por los asalariados y cesantes

Fuente: EL TIEMPO, Bogotá, 1930 a 1934. Archivo General de la Nación, Fondo República, sección $1^{\circ}$ Ministerio de Gobierno.

Así, es bastante prometedora la tesis de que existe una relación inversamente proporcional entre el comportamiento de la economía y el comportamiento de los trabajadores asalariados. A una fase de recuperación o auge económico se le acomoda una etapa de agitación social y a una fase de recesión o depresión económica se le acomoda una etapa de hibernación social.

En lo que se refiere a los motivos que agitaron el paisaje social es claro que surge una gama de siete grandes razones de conmoción: aumento salarial, el 60\%; búsqueda de trabajo, el 17\%; reducción salarial, el 8\%; seguridad social, el 4\%; evitar despidos, el 2\%; evitar la adquisición de maquinas, el $2 \%$; solidaridad con huelguistas, el $2 \%$ y un $4 \%$ sin registro del motivo (véase Tabla 7). Y en consonancia con la tesis sugerida en el párrafo anterior, se nota que 13 de las 46 acciones de protesta caen en los años de la depresión propiamente dicha, mientras las restantes 33 suceden a partir de 1933, cuando se vislumbran síntomas de recuperación. Eso hace que el $28 \%$ del inconformismo de los asalariados urbanos venga de la mano con un ciclo de vacas flacas y el $72 \%$ restante con un ciclo de vacas gordas, mucho más evidente si se visualiza que las razones del malestar social dentro del primer ciclo tienen relación con exigencias de trabajo, exactamente 7 de las 13 , el $54 \%$ y tres, el $23 \%$, con el esfuerzo de evitar el decrecimiento del sueldo. 
Tabla No. 7. Motivos de las huelgas y movilizaciones de los trabajadores asalariados $(1930$ - 1934)

\begin{tabular}{|l|c|c|c|c|c|}
\hline Motivo & $\mathbf{1 9 3 0}$ & $\mathbf{1 9 3 1}$ & $\mathbf{1 9 3 2}$ & $\mathbf{1 9 3 3}$ & $\mathbf{1 9 3 4}$ \\
\hline Aumento salarial & 0 & 0 & 1 & 14 & 12 \\
\hline Búsqueda de trabajo & 7 & 0 & 1 & 0 & 0 \\
\hline Reducción salarial & 3 & 0 & 0 & 1 & 0 \\
\hline Seguridad social & 0 & 0 & 0 & 1 & 1 \\
\hline Evitar despidos & 1 & 0 & 0 & 0 & 0 \\
\hline Evitar compra de máquinas & 0 & 0 & 0 & 0 & 1 \\
\hline Solidaridad gremial & 0 & 0 & 0 & 0 & 1 \\
\hline Desconocido & 0 & 0 & 0 & 1 & 1 \\
\hline
\end{tabular}

Fuente: EL TIEMPO, Bogotá, 1930 a 1934. Archivo General de la Nación, Fondo República, sección $1^{\circ}$ Ministerio de Gobierno.

Entre tanto, las acciones del segundo ciclo revelan que los trabajadores pretenden arañar una mejor remuneración de la mano de obra porque perciben un comportamiento favorable de la economía y el sector en el que se desempeñan. A continuación se hará una descripción sucinta de los objetivos concretos inherentes a los dos primeros motivos que agitaron el ambiente social de los trabajadores asalariados.

\section{Acciones por aumento salarial}

La única forma de acción de los trabajadores en procura de mejores salarios fue la huelga. La oleada empieza a finales de 1932 y se cierra en agosto de 1934 (véase tabla 7). La huelga que abre la puerta del dinamismo obrero fue la declarada por los asalariados panificadores de Bogotá el 16 de diciembre, momento en el que se rompe el diálogo con los patronos agremiados en el Consorcio de Panaderos debido a que su oferta de incremento no satisfizo sus expectativas. La huelga que cerró el período fue la proclamada por los obreros tipógrafos de la Casa Mogollón de Barranquilla el 25 de agosto. Entre una y otra huelga los anales de la protesta social asalariada fueron escritos por trabajadores del sector del transporte y la industria de bienes de consumo (véase Tabla 8 en la página 120).

De acuerdo con el orden de la Tabla 8, pero sin especificar el cometido de cada una de las huelgas, podemos establecer estas aspiraciones salariales en 1933: los braceros de La Dorada quieren aumento del precio de la carga y descarga de cada bulto de 3 a 7 centavos. Los braceros de Caracolí reclaman les suban de 40 a 60 centavos la carga y descarga de cada tonelada. Los braceros en Barranquilla exigen a las diferentes empresas navieras un aumento mínimo del 40\%, tomando como referencia base de los jornales $\$ 1,25$ y $\$ 1,50$ diarios, además de la jornada de 8 horas y asistencia médica.

Los huelguistas del Ferrocarril del Pacífico solicitan incremento del 30\% de los salarios y descanso remunerado los sábados a partir del medio día. Los braceros del Ferrocarril de Puerto Colombia no solamente demandan reajuste del salario, sino el establecimiento de una tabla para el pago de las horas extras. Los obreros de la fábrica Fenicia le apuntan a un ajuste del $30 \%$, al igual que los trabajadores de la fábrica de zapatos La Corona para los jornales menores de un peso diario, de un $25 \%$ para los que devengan entre uno y dos pesos y $15 \%$ para salarios mayores de dos pesos.

En lo concerniente a 1934 tenemos estas peticiones: las escogedoras de una trilladora de Ibagué reclaman mejor jornal y el mantenimiento de obreros a fin de movilizar el café. Los obreros del Ferrocarril de Caldas más sueldo y la certeza 
Tabla No. 8. Huelgas por aumento salarial (1930 - 1934)

\begin{tabular}{|c|c|}
\hline HUELGA & FECHA \\
\hline Obreros panificadores & Diciembre 1932 \\
\hline Braceros de La Dorada & Marzo 1933 \\
\hline Obreros zapateros & Abril 1933 \\
\hline Braceros de Caracolí & Octubre 1933 \\
\hline Braceros en Barranquilla & Octubre 1933 \\
\hline Braceros de Girardot & Octubre 1933 \\
\hline Obreros zapateros & Noviembre 1933 \\
\hline Braceros de Puerto Liévano & Noviembre 1933 \\
\hline Obreros del Ferrocarril del Pacífico & Noviembre 1933 \\
\hline Braceros de Puerto Colombia & Noviembre 1933 \\
\hline Obreros de la cervecería Bavaria & Noviembre 1933 \\
\hline Obreros de la cervecería Germania & Noviembre 1933 \\
\hline Obreros Fábrica Fenicia de vidrio & Noviembre 1933 \\
\hline Obreros zapateros & Noviembre 1933 \\
\hline Braceros de La Dorada & Diciembre 1933 \\
\hline Obreros zapateros & Diciembre 1933 \\
\hline Obreros obras públicas & Enero 1934 \\
\hline Obreros zapateros & Enero 1934 \\
\hline Escogedoras de café & Abril 1934 \\
\hline Obreros del Ferrocarril del Nordeste & Mayo 1934 \\
\hline Obreros Fábrica de textiles Monserrate & Mayo 1934 \\
\hline Obreros del Ferrocarril de Antioquia & Junio 1934 \\
\hline Obreros del Ferrocarril de Caldas & Junio 1934 \\
\hline Obreros albañiles & Junio 1934 \\
\hline Braceros Puerto Liévano & Julio 1934 \\
\hline Braceros de Girardot & Julio 1934 \\
\hline Escogedoras de café & Julio 1934 \\
\hline Obreros zapateros & Agosto 1934 \\
\hline Obreros tipógrafos & Agosto 1934 \\
\hline
\end{tabular}

Fuente: EL TIEMPO, Bogotá, 1930 a 1934. Archivo General de la Nación, Fondo República, sección $1^{\circ}$ Ministerio de Gobierno.

de que la empresa no va a tomar represalias contra los huelguistas. Los braceros de Puerto Liévano, tomando el ejemplo de los braceros de Puerto Colombia, van detrás de un aumento del jornal y la fijación de una tabla para las horas extras que funcione con una tarifa que se recargará con un $25 \%, 50 \%$ o $100 \%$ cuando el trabajo se verifique entre las seis y las nueve de la noche, las nueve y las doce o desde la media noche hasta las seis de la mañana del siguiente día.

\section{Acciones por búsqueda de trabajo}

La forma de acción dominante fue la movilización o manifestación pacífica, a diferencia de la 
huelga que fue el instrumento de petición y presión clásico de los obreros para conquistar sus demandas de salarios superiores y otros requeri-mientos conexos. Sólo 3 de las 8 acciones enmarcadas en este conjunto tomaron una senda distinta: la asonada. El ciclo se despliega entre enero y septiembre de 1930, con un estallido adicional y solitario en enero de 1932 (Véase Tabla 9).

Tabla No. 9. Movilizaciones y asonadas por búsqueda de trabajo (1930 - 1934)

\begin{tabular}{|l|l|}
\hline ACCIÓN & FECHA \\
\hline Asonada & Enero 1930 \\
\hline Movilización & Marzo 1930 \\
\hline Movilización -Asonada & Marzo 1930 \\
\hline Movilización & Abril 1930 \\
\hline Movilización & Septiembre 1930 \\
\hline Movilización & Septiembre 1930 \\
\hline Asonada & Septiembre 1930 \\
\hline Movilización & Enero 1932 \\
\hline
\end{tabular}

Fuente: EL TIEMPO, Bogotá, 1930 a 1934.

La primera movilización tuvo lugar el 17 de marzo en la ciudad de Medellín, que por aquel entonces era la cuarta ciudad más poblaba del país, alrededor de 120.000 habitantes, frente a los 235.427 de Bogotá, los 139.974 de Barranquilla y los 122. 847 de Cali (El Colombiano, № 5086, 1930, 25 de agosto). La marcha se detuvo ante las instalaciones del Banco Alemán Antioqueño porque los desocupados se enteraron de que el gobernador estaba adelantado trámites para adquirir un crédito con destino a la continuación de los trabajos en varias carreteras del departamento.

La segunda movilización discurre en la misma ciudad tres días después, empieza en el parque Berrío y va encaminándose hacia la Asamblea y el Consejo con el ánimo de requerir medidas eficaces para solventar el gravísimo problema social del desempleo, pero a medida que las expectativas de los participantes declina, el disgusto, la desazón, la impotencia y la pesadumbre coparon el aliento popular, hasta el punto de perderse la calma reinante y devenir en una asonada que puso como blanco varios establecimientos comerciales, financieros e industriales con un saldo trágico de víctimas: un muerto y numerosos heridos (El Tiempo, №6635, 1930, 31 de marzo 31).

La muchedumbre agolpada en el parque Berrío percibió que el desempleo imperante era, en parte, producto de la falta de diligencia de los gobiernos departamental y municipal, por lo que el discurso pronunciado por el diputado Darío Botero ante la masa cuando esta arribó al edificio de la Asamblea Departamental con la idea de bajarle intensidad a la furia popular, desencadenaría el efecto contrario, pues la gente contestó que deseaba hechos y no palabras, a lo que siguió una andanada de piedras de la que salieron heridos 2 policías y 3 manifestantes, hasta que nuevamente la masa se puso en movimiento rumbo al palacio municipal, donde la historia de frustración e ira se repitió otorgándole a la multitud el combustible suficiente para emprender la destrucción de las vitrinas de establecimientos comerciales y bancarios, especialmente ferreterías en búsqueda de armas, aunque de la furia popular no escapó una planta de pasteurización, por lo cual la policía toma la decisión de dispersar la masa por la fuerza y dispara contra ella, el 
saldo fue, 1 manifestante muerto, numerosos heridos y 26 arrestados.

La tercera movilización popular data del 5 de abril de 1930, ocurrió en Neiva frente a la Asamblea Departamental, la cual exigió de los diputados y del Gobernador medidas de generación de trabajo. Un diputado tomó la vocería indicando que había elaborado un proyecto de ordenanza en compañía de los hacendados e industriales de la región para impulsar la industria agrícola hasta que los cesantes puedan convertirse en propietarios de tierra (El Tiempo, $\mathrm{N}^{\circ}$-6651, 1930, 6 de abril).

La cuarta manifestación ocurre el 1- de septiembre en Bucaramanga y, al igual que todas las anteriores, los manifestantes terminan su gesta en las instalaciones del gobierno departamental, sin embargo, puede apreciarse una gran diferencia, el Gobernador García Cadena, satisface las expectativas de la masa anunciándoles que a partir del día siguiente se iniciaran trabajos en la carretera del noroeste ocupando 600 obreros (El Tiempo, № 6795, 1930, 2 de septiembre 2).

La quinta movilización sucedió el 9 de septiembre en Barranquilla. Un grupo considerable de 800 desocupados se situó frente a la Gobernación gritando "tenemos hambre", a lo que el recién posesionado gobernador Pumarejo, contestó que se esforzaría por conseguir de los empresarios dineros para adelantar un vasto plan de obras públicas (EL TIEMPO, №-6804, 1930, 11 de septiembre).

El final del ciclo de la protesta por trabajo concierne a la asonada ocurrida la mañana del 15 de septiembre en Barranquilla. Los amotinados asaltaron varios almacenes, rompiendo puertas y vitrinas para apoderarse de la mercancía. $\mathrm{El}$ ataque más fuerte fue contra los almacenes de los comerciantes italianos Pacini y Citarella. El saqueo enfrentó a la policía con los saqueadores, uno de los cuales murió.

Al final de la turbulenta jornada un grupo de empresarios encabezados por Evaristo Obregón,
Ángel Palma, Alberto Roncallo y Francisco Carbonell, temerosos de que pudiera repetirse el funesto suceso, acordaron suscribir un capital de $\$ 30.000$ que se le entregaría a la gobernación en calidad de préstamo sin intereses para iniciar los trabajos de la carretera a Puerto Colombia en el curso de la semana y bajarle ímpetu al enojo de los desocupados (EL TIEMPO, N- 6809, 1930, 16 de septiembre).

\section{Conclusiones}

El perfil de la agitación social durante el gobierno del Presidente Enrique Olaya Herrera pone de presente que el dinamismo social estuvo supeditado a las acciones emprendidas por dos sectores sociales: asalariados y estudiantes, en consonancia con lo acontecido desde principios de siglo y en sincronía con lo que va a acontecer desde el gobierno de la revolución en marcha hasta el inicio del nuevo milenio, de acuerdo con lo que nos presenta el investigador Mauricio Archila, al indicar que entre los años 1975 y 2000 el peso de los actores sociales en la protesta se distribuyó de la siguiente forma: trabajadores asalariados $34 \%$, pobladores urbanos $28 \%$, campesinos e indígenas $17 \%$, estudiantes $16 \%$ y el resto de actores 5\% (Archila, 2002).

De esta manera, se toma de referencia el fin de la Guerra de los Mil Días y el principio de la administración liberal de Alfonso López Pumarejo en agosto de 1934, donde es visible una tendencia ascendente de la agitación social, sin descartar la inclusión de períodos de flujo y reflujo de dichas expresiones sociales, como aconteció con las huelgas efectuadas en consecución de mejores salarios, que cayeron durante el ciclo de la recesión entre 1930 y 1932 para retomar aire apenas se entra en un ciclo de recuperación a fínales de este último año. Tendencia ascendente mucho más visible si se compara el volumen de las acciones de principios del siglo XX con las que se pudieron escenificar en el siglo XIX, circunstancia que guarda relación con la combinación de una serie de factores endógenos y exógenos que se acentuaron con el arribo del nuevo siglo. 
Entre los factores endógenos figuran la transformación progresiva de la composición de la actividad productiva en la cual el formato agropecuario y minero se ve acompañado del despegue industrial basado en empresas de bienes de consumo alimentadas por capital doméstico proveniente del comercio exterior y la minería. La aclimatación de las relaciones de trabajo asalariado en la industria, la agricultura comercial, la actividad petrolera de enclave, el transporte fluvial y marítimo y las obras públicas.

La tonificación de la inversión directa de capital en sector primario de exportación. El relativo fortalecimiento de la infraestructura férrea y vial para seguir articulando los mercados locales y regionales. El advenimiento de fuerzas políticas de oposición a los dos partidos tradicionales como el Partido Obrero Colombiano y el Partido Socialista Revolucionario, que más adelante se convertiría en el Partido Comunista, que a su vez implicaría la presencia de gente ilustrada que abrió su mente a doctrinas proclives a adoptar y defender ideas de justicia social que algunas veces vinieron del socialismo y otras de la Revolución Francesa.

Entre los factores exógenos cabe anotar el inobjetable triunfo del socialismo ruso al colocarse como alternativa del capitalismo industrial y paradigma político de las clases trabajadoras del mundo entero; el ejemplo de los estudiantes de Córdoba; la llegada de extranjeros que trajeron consigo ideas de justicia social, entre los que se contó el líder de la Liga de Inquilinos de Barranquilla, Nicolás Gutarra, expulsado del país por considerársele extranjero "pernicioso" y el ciudadano italiano Leonardo Macelli, secretario de la Unión Sindical Soviética, censurado por agitar las masas y promover la huelga de zapateros ocurrida en Cali en 1934, corriendo idéntica suerte que Gutarra (EL TIEMPO, No 8163, 1934, 22 de mayo). Este conjunto amplio y diverso de factores derivó en una explosiva amalgama que abrió un gran boquete a la paquidérmica, limitada y opresiva estructura social heredada del siglo XIX.
De esta manera, Colombia obtuvo un pase permanente a los avatares sociales intrínsecos del proceso de modernización o transformación capitalista, es decir, a la lucha de clases entre el trabajo asalariado y los dueños del capital, a las querellas entre los trabajadores públicos y el Estado, al igual que entre la población procedente de todas las capas sociales y el Estado por servicios públicos, transporte e infraestructura. La fórmula de contestación, tanto espontánea como organizada de la masa proveniente de múltiples orígenes sociales, especialmente proletaria, irá adquiriendo la mayoría de edad y con ella la carta de ciudadanía.

Una situación es bastante clara no solamente para los años del gobierno de Olaya Herrera, sino para lo que va corrido del nuevo silgo XX, es la protesta y la agitación social que se visibiliza, emerge una fuerte tendencia a tomar y copar espacios públicos y privados que confrontan el papel asumido por el Estado, por los empresarios y por las instituciones educativas. Es evidente la presencia de un sentimiento y sentido de rebeldía en cuanto a que es lícito, legítimo y apropiado pronunciarse abierta y contundentemente contra los grupos sociales y las instituciones que por acción u omisión lesionan o puedan lastimar los derechos que por justa causa y razón los acompañan.

Existe una especie de certeza social de la necesidad de defender y ampliar espacios sociales que vienen conquistándose desde años atrás, plasmados en la interlocución gremial y política de asalariados, campesinos y estudiantes frente al Estado, los capitalistas, los intelectuales y el resto de la sociedad mediante acciones de confrontación o divulgación.

Esta conquista social y política es una renta histórica medible o cuantificable con el número de protestas sociales en cualquiera de las formas anotadas: movilizaciones, mítines, paros, reyertas, huelgas de hambre, concentraciones, etc., registradas a lo largo del siglo XIX y las acontecidas durante las tres y medias décadas corridas del siglo $\mathrm{XX}$, lo que nos da a pensar que si bien 
continuaron adoptándose una variada gama de medidas de fuerza para controlar y reprimir la protesta: despidos, arrestos arbitrarios, amenazas, estado de sitio y uso de las armas, el régimen político es más permeable a los nuevos acontecimientos sociales.

Los gobiernos conservadores y liberales nunca fueron absolutamente impermeables a las reformas sociales que la modernización exigía. El punto era que la rebeldía de los sectores sociales más volátiles o proclives a la confrontación pudieran controlarse políticamente sin desmedro del orden burgués que seguía cocinándose a fuego lento desde mediados del siglo XIX, época de las reformas liberales ocurridas en la Nueva Granada entre 1847 y 1861 que pretendieron "despejar el camino hacia el desarrollo y la modernidad" (Aguilera y Vega, 1991,p.97).

Otro aspecto rescatable de las acciones sociales de inconformismo, es el nivel de confrontabilidad exhibido. Según una escala tomada por el investigador del CINEP Mauricio García Durán, del escritor John Lofland, la inmensa mayoría de protestas registradas en nuestra base de datos clasifican en los niveles medio y alto (véase Tabla 12). Son acciones colectivas que corresponden a asonadas, nivel general alto y específico 10; huelgas y paros, nivel general alto y específico $7 \mathrm{y}$, movilizaciones, nivel general medio y específico 5 .

Tabla No. 12. Nivel de confrontabilidad

\begin{tabular}{|l|l|l|}
\hline Nivel general & Nivel Específico & Tipos de acciones correspondientes a cada nivel \\
\hline Alto & Nivel 10 & Acciones que derivan en confrontación violenta \\
& Nivel 9 & Tomas y bloqueos \\
& Nivel 8 & Acciones de resistencia civil pacífica \\
& Nivel 7 & Paros y huelgas \\
\hline Medio & Nivel 6 & Zonas de paz \\
& Nivel 5 & Marchas y concentraciones \\
& Nivel 4 & Diálogo y negociaciones \\
\hline Bajo & Nivel 3 & Encuentros, foros y seminarios \\
& Nivel 2 & Actos culturales y deportivos \\
& Nivel 1 & Campañas educativas \\
\hline
\end{tabular}

Fuente: García Durán (2005. p.154).

Además, es patente que las acciones colectivas de protesta cometidas por los trabajadores cesantes, los inquilinos y los estudiantes se encaminaron a dar a conocer sus respectivas inquietudes y problemáticas a las autoridades civiles de lo distintos niveles administrativos. Los cesantes confiaban o por lo menos golpeaban la puerta de las autoridades ejecutivas y legislativas regionales y locales. Las demandas de trabajo eran enunciadas ante las instalaciones de los órganos legislativos de la Asamblea Departamental y el Consejo Municipal o del ejecutivo regional.
Los estudiantes universitarios y de secundaria llevaban sus quejas ante las autoridades escolares de la respectiva institución en conflicto, aunque en unos pocos contados casos concurrieron a instituciones de los poderes ejecutivo y legislativo regional o nacional. Recuerdo que el 27 de abril de 1930 los estudiantes universitarios de Cartagena ventilaron sus aspiraciones ante la Asamblea Departamental y 3 días más adelante los estudiantes de bachillerato del Colegio Barranquilla llevan sus pretensiones al despacho del Gobernador. 
Los inquilinos en Bogotá, el 22 de septiembre de 1930 ambicionaban del Congreso de la República la aprobación de un proyecto de ley sobre arrendamiento que los protegiera de las arbitrariedades rentísticas de los propietarios de los inmuebles.

En general, los sectores sociales mencionados actuaron con la voluntad de llamar la atención de las autoridades legítimamente constituidas para hallar una salida rápida y eficaz de sus contrariedades; creían que los poderes ejecutivo y legislativo, sobre todo a nivel regional, tenían una considerable parte de la fórmula de solución de sus problemas, lo que es casi lo mismo a decir que confiaban en las instituciones republicanas de poder burgués y en su arbitraje objetivo a favor de las causa de los justos y menesterosos.

De igual manera, es obvio que las acciones colectivas de inconformismo discurren en medio de una vía de expresión formal ceñida a derecho, en cuanto a que reconocen y aceptan el orden jurídico y político imperante, así como la funcionabilidad de las instituciones, de lo contrario jamás hubiesen acudido en su ayuda.

Además, estiman que las autoridades civiles locales y regionales estacionadas en la cúspide del poder público deben cumplir con el compromiso de encontrar remedios cuando las instancias inferiores dilatan o entorpecen la gestión administrativa pública y privada en beneficio de la gobernabilidad, entendida esta última como la capacidad de las instituciones y la burocracia para atender y reparar las exigencias de la comunidad en calidad de sujeto actuante o de arbitro.

\section{Referencias}

Aguilera, M. \& Vega, R. (1991). Ideal democrático y revuelta popular. Bogotá D.C.: Instituto María Cano.

Archila, M. (2005). Idas y venidas, vueltas y revueltas 1958 - 1990. Bogotá D.C.:
Instituto Colombiano de antropología e Historia, Centro de Investigación y Educación Popular.

Archila, M. (2002, noviembre - diciembre). Colombia en el cambio de siglo: actores sociales, guerra y política 1975 -2000. Revista Nueva Sociedad, 182, 76-90.

Cardoso. F. \& Pérez, H. (1977). Los métodos de la historia. México D.F.: Editorial Grijalbo.

Farinetti, M. (2002). "La conflictividad social después del movimiento obrero". Revista Nueva Sociedad, 182, 60-75.

Fontana, J. (1982). Historia, análisis del pasado y proyecto social. Barcelona: Editorial Grijalbo.

Foucault, M. (2003). "Volver a la historia". Revista Veredas, 7, 7-19.

García, M. (2005, junio). Repertorio de acciones colectivas en la movilización por la paz en Colombia 1978 - 2003. Revista Controversia, 184, 150-176.

Avella, M; Bernal, J; Errázuriz, M. \& Ocampo, J. (1991). La consolidación del capitalismo moderno. En J. A. Ocampo (Ed.), Historia económica de Colombia (pp. 243-332). Bogotá D.C.: Siglo Veintiuno Editores.

Rudé, G. (1979). La multitud en la historia. (3ra Ed.). Madrid: Siglo Veintiuno editores.

Rudé, G. (1983). La Europa revolucionaria 1783 - 1815. (6ta Ed.). Madrid: Siglo Veintiuno editores.

Torrejano, R. (2007). La protesta urbana en Colombia a principios del siglo XX 1902 1930. En R. H. Torrejano (Ed.), Cuatro ensayos sobre historia social y política de Colombia en el siglo XX (pp. 21-73). Bogotá D.C.: Universidad Jorge Tadeo Lozano. 


\section{Publicaciones periódicas}

El Tiempo, Bogotá, 1930 - 1934

El Colombiano, Medellín, 1930.

Archivo General de la Nación, Fondo república, Sección 1-Ministerio de Gobierno 